\title{
Efficient extraction of drainage networks from massive, radar-based elevation models with least cost path search
}

\author{
M. Metz ${ }^{1}$, H. Mitasova ${ }^{2}$, and R. S. Harmon ${ }^{3}$ \\ ${ }^{1}$ Institute of Experimental Ecology, University of Ulm, Ulm, Germany \\ ${ }^{2}$ Department of Marine, Earth and Atmospheric Sciences, North Carolina State University, Raleigh, North Carolina, USA \\ ${ }^{3}$ Environmental Sciences Division, Army Research Office, US Army Research Laboratory, Durham, North Carolina, USA
}

Received: 22 April 2010 - Published in Hydrol. Earth Syst. Sci. Discuss.: 27 May 2010

Revised: 1 December 2010 - Accepted: 11 February 2011 - Published: 25 February 2011

\begin{abstract}
The availability of both global and regional elevation datasets acquired by modern remote sensing technologies provides an opportunity to significantly improve the accuracy of stream mapping, especially in remote, hard to reach regions. Stream extraction from digital elevation models (DEMs) is based on computation of flow accumulation, a summary parameter that poses performance and accuracy challenges when applied to large, noisy DEMs generated by remote sensing technologies. Robust handling of DEM depressions is essential for reliable extraction of connected drainage networks from this type of data. The least-cost flow routing method implemented in GRASS GIS as the module r.watershed was redesigned to significantly improve its speed, functionality, and memory requirements and make it an efficient tool for stream mapping and watershed analysis from large DEMs. To evaluate its handling of large depressions, typical for remote sensing derived DEMs, three different methods were compared: traditional sink filling, impact reduction approach, and least-cost path search. The comparison was performed using the Shuttle Radar Topographic Mission (SRTM) and Interferometric Synthetic Aperture Radar for Elevation (IFSARE) datasets covering central Panama at $90 \mathrm{~m}$ and $10 \mathrm{~m}$ resolutions, respectively. The accuracy assessment was based on ground control points acquired by GPS and reference points digitized from Landsat imagery along segments of selected Panamanian rivers. The results demonstrate that the new implementation of the least-cost path method is significantly faster than the original version, can cope with massive datasets, and provides the most accurate results in terms of stream locations validated against reference points.
\end{abstract}

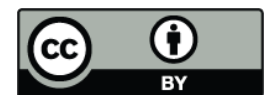

Correspondence to: $\mathrm{M}$. Metz (markus.metz@uni-ulm.de)

\section{Introduction}

Shuttle Radar Topographic Mission (SRTM; Farr et al., 2007) and various airborne Interferometric Synthetic Aperture Radar for Elevation (IFSARE) surveys provide a new generation of elevation data in regions that have had only limited, often low resolution coverage. These topographic data sets are increasingly used to improve mapping of geomorphic and hydrologic features, especially in remote, hard to reach areas and at regional to global scales (e.g., Kinner et al., 2005; Lehner and Döll, 2004; World Wildlife Fund, 2009).

In spite of significant advances in the development of flow routing algorithms (e.g. Quinn et al., 1991; Costa-Cabral and Burges, 1994; Holmgren, 1994; Quinn et al., 1995; Tarboton, 1997), accurate extraction of drainage networks from Digital Elevation Models (DEMs) generated by remote sensing technologies such as SRTM or IFSARE remains challenging. To fully understand the problem, it is important to realize that the mapped elevation surfaces include the top of the forest canopy, as well as anthropogenic features, rather than the ground surface required for flow routing. Although homogeneous forest canopy generally follows the shape of the ground surface, gaps in vegetation that can stretch over hundreds of meters create large, often nested, depressions that pose difficulties for flow routing. In addition to these large depressions, the surface over forested areas is noisy, creating numerous small depressions and barriers that further complicate drainage network extraction. Therefore, one of the important questions investigated in this paper was whether such data are suitable for drainage network extraction at all and if yes, how accurate are the extracted drainage networks and which methods provide the most reliable results.

At the same time, the broad availability of elevation data dramatically increased the extent of regions that can be analyzed at relatively high resolutions, given the computational capabilities that can support processing of massive DEMs.

Published by Copernicus Publications on behalf of the European Geosciences Union. 
Therefore, significant effort has been devoted to the development of new flow tracing and watershed analysis algorithms that support efficient processing of large DEMs and address the issue of routing through complex nested depressions (e.g. Rivix Limited Liability Company, 2001; Arge et al., 2003; Danner et al., 2007).

The most widespread method for handling depressions is sink filling, up to the level of the sink spill point, combined with routing through the resulting flat area (Jenson and Domingue, 1988; Fairfield and Leymarie, 1991; Planchon and Darboux, 2001; Wang and Liu, 2006). Improved sink filling methods (e.g. Garbrecht and Martz, 1997; Grimaldi et al., 2007; Santini et al., 2009) first fill sinks, and then introduce a gradient to all flat areas to provide non-zero gradients for flow routing. The method complementary to sink filling is carving or breaching (Rieger, 1998; Martz and Garbrecht, 1998) where a channel is carved out of each sink, breaking through the (artificial) obstacle. Both principles can be combined in an impact reduction approach (IRA; Lindsay and Creed, 2005) that for each sink determines the method that causes the least impact on the source dataset. All these approaches alter the elevation data in order to ensure full drainage, assuming that sinks are artifacts created either by too low (artificial pits) or too high (artificial drainage blocks) elevation values.

An alternative to the modification of elevation data is to determine the least-cost drainage paths (LCP) through unaltered terrain and out of sinks. LCP search methods were generally designed to find the shortest or fastest route from a starting point to a given destination, used for example in car navigation devices or to generate cumulative cost surfaces. A particular LCP search method (A* Search; Hart et al., 1968) was adapted for flow routing and watershed analysis and implemented as the module r.watershed (Ehlschlaeger, 1989) in GRASS GIS (Neteler and Mitasova, 2008, see GRASS Development Team 2010 for binaries and source code). When applied to IFSARE derived DEMs, this approach has provided more accurate flow routing through large, nested depressions with fewer artifacts than traditional sink filling (Kinner et al., 2005). However, the module was not designed to handle the massive DEMs that are currently available (Arge et al., 2003). To render the module suitable for analysis of very large datasets at ever higher resolutions, and to reduce the artifacts in flow patterns due to the single flow direction (SFD) algorithm (Quinn et al., 1991; Holmgren, 1994; Tarboton, 1997), redesign of the implementation and addition of more flow routing options was necessary.

In this study, we present substantial improvements to the LCP method implementation and evaluation of its efficiency and accuracy when applied to radar-based DEMs. We compare the performance of the improved module with (1) its original implementation, (2) a module based on a disk input/output (I/O) efficient method (Arge et al., 2003), and (3) the IRA implementation in the Terrain Analysis System (TAS, Lindsay and Creed, 2005). We also analyze the impact of mapping technology (IFSARE, SRTM), resolution, and DEM resampling on the accuracy of the extracted drainage networks. Although the LCP method has been used since early 90ies, the literature that describes the algorithm, its implementation and properties is very limited (Ehlschlaeger, 1989). This paper aims to fill this gap in literature and to highlight the value of this method and its improvements for analysis of modern DEMs.

\section{Methods}

\subsection{Improved least cost path search algorithm}

The LCP algorithm (A* Search, Hart et al., 1968; Ehlschlaeger, 1989) used for flow routing, flow accumulation, and watershed analysis of raster-based DEMs was redesigned to increase the processing speed and decrease memory consumption. The implementation in the GRASS module r.watershed (Fig. 1) starts with potential outlet points. Natural ultimate outlets are e.g. river mouths opening into oceans or lakes without outflow. On gridded elevation models, potential outlets are grid cells along the map boundaries or cells with at least one neighbor with unknown elevation, e.g. masked ocean. All potential outlet grid points are inserted into a list sorted by costs. Costs are measured as elevation and order of addition to the sorted list (grid cells added earlier have higher precedence in case of equal elevation). For the actual search, the grid cell with the lowest elevation (smallest cost) is extracted and removed from the sorted list, marked as processed and its neighbors are investigated. This causes the search to proceed along the least steep uphill slope. At each step during the search, only neighboring grid cells that are not yet in the search list and not yet processed are added to the list, and drainage direction for these neighboring grid cells is set towards the current grid cell. If a depression is encountered, the search follows the steepest downhill slope to the bottom of a depression and then proceeds again along the least steep uphill slope. The search proceeds in this manner upstream along the least steep slope and terminates when all grid points have been processed. The LCP search provides two results: (a) flow direction for each cell in a standard D8 manner (O'Callaghan and Mark, 1984), and (b) the order in which cells must be processed for flow accumulation.

The search component of the original implementation was modified by augmenting it with a minimum heap used as priority queue (Atkinson et al., 1986; Metz and Ehlschlaeger, 2010), which led to a substantial speed improvement. In the original implementation, the time needed to keep the sorted list sorted increased exponentially with the number of grid cells, while in the new implementation this time increase is logarithmic. Removal of redundant information in intermediate data as well as reduced memory requirements for both the search and the flow accumulation components 


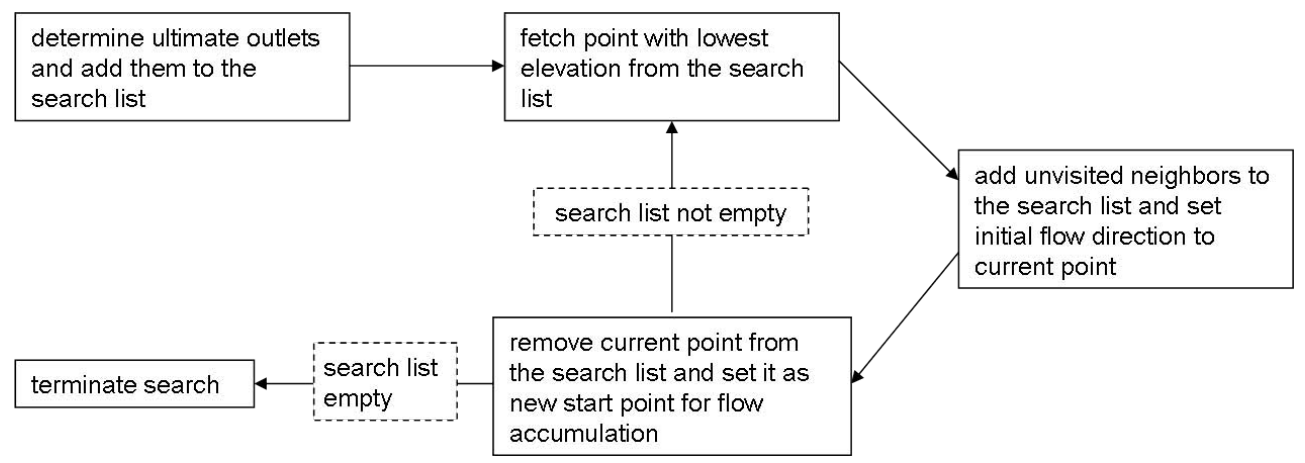

Fig. 1. Flowchart illustrating the least cost path search algorithm.

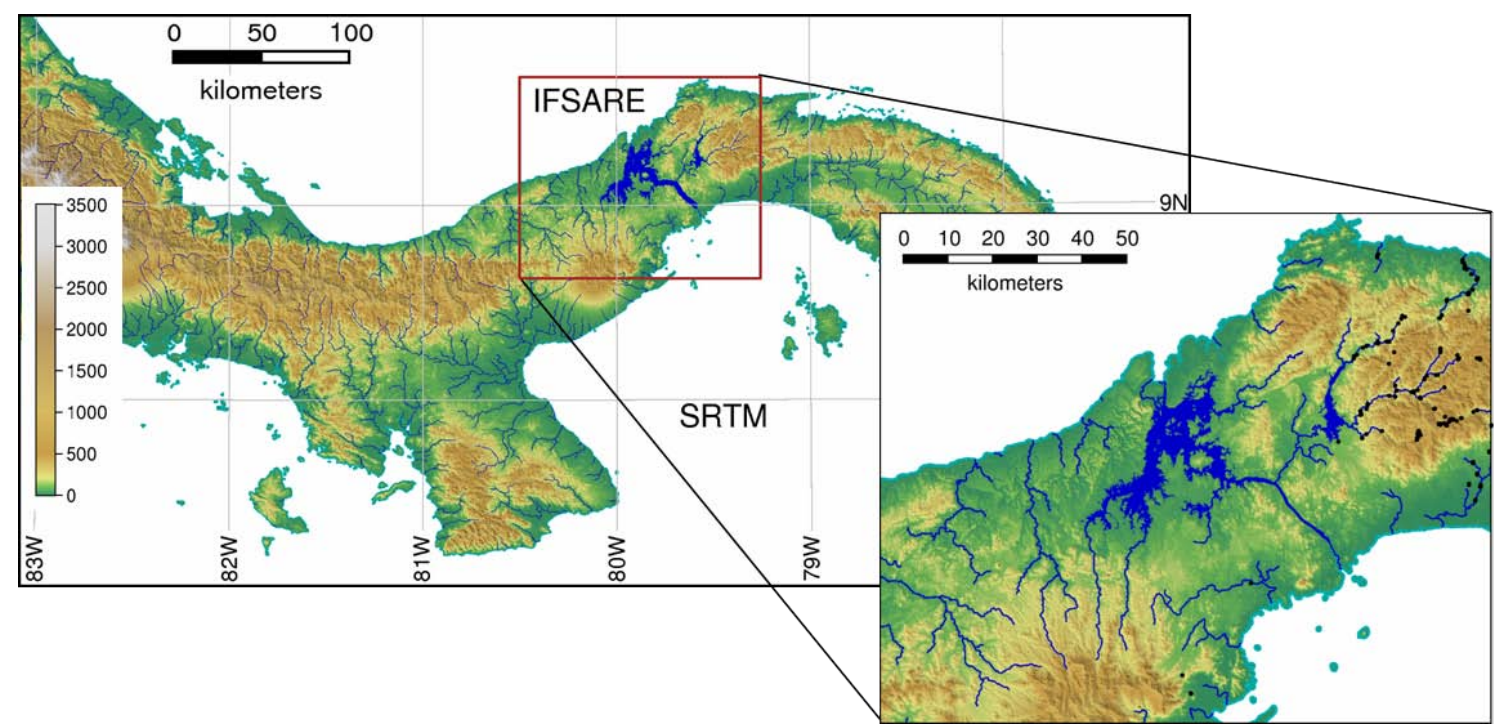

Fig. 2. SRTM and IFSARE coverage of Panama. GPS ground control points are displayed in black.

have further enhanced the module's capacity to process larger DEMs. For massive datasets that can not be processed with the amount of memory available, the module can optionally use external memory with intermediate data stored on disk. These changes, aimed at improving the computational performance, did not affect the quality of the results.

To improve the flow routing accuracy and to reduce artifacts in the flow accumulation pattern, a multiple flow direction (MFD) algorithm, based on Holmgren (1994), was implemented using the order determined by the LCP search with an option to control the strength of flow convergence. For grid-based elevation models, an MFD approach conforms better to theoretical surface flow dispersion than single flow direction in which only one neighboring cell can receive surface flow from the current cell (Freeman, 1991; Quinn et al., 1991; Holmgren, 1994; Tarboton, 1997). Initial D8 flow directions as determined by the LCP search are used to route flow out of depressions when all unprocessed neighboring grid cells have higher elevation than the current grid cell.

\subsection{Elevation data}

Two different sources of elevation data were used to demonstrate the improvements in the LCP method (Fig. 2). Countrywide elevation coverage of Panama was available as a 3 arc second resolution SRTM DEM (Farr et al., 2007). SRTM version 2.1 provided by the NASA Jet Propulsion Laboratory (http://www2.jpl.nasa.gov/srtm/, download at http://dds.cr.usgs.gov/srtm/) was selected for this study as the most reliable version in terms of accuracy and minimal artifacts, after evaluating properties of the SRTM products available at the time of writing (v1, v2.1, v3, v4.1). The published absolute vertical error of the version 2.1 SRTM DEM is $6.2 \mathrm{~m}$ for South America including Panama (Farr et al., 2007), although several studies report higher accuracies (see e.g. Rodriguez et al., 2006). A recent airborne IFSARE survey has provided new, more detailed information about the topography in central Panama at $10 \mathrm{~m}$ resolution, using technology with published vertical accuracy of $\sim 3 \mathrm{~m}$ 


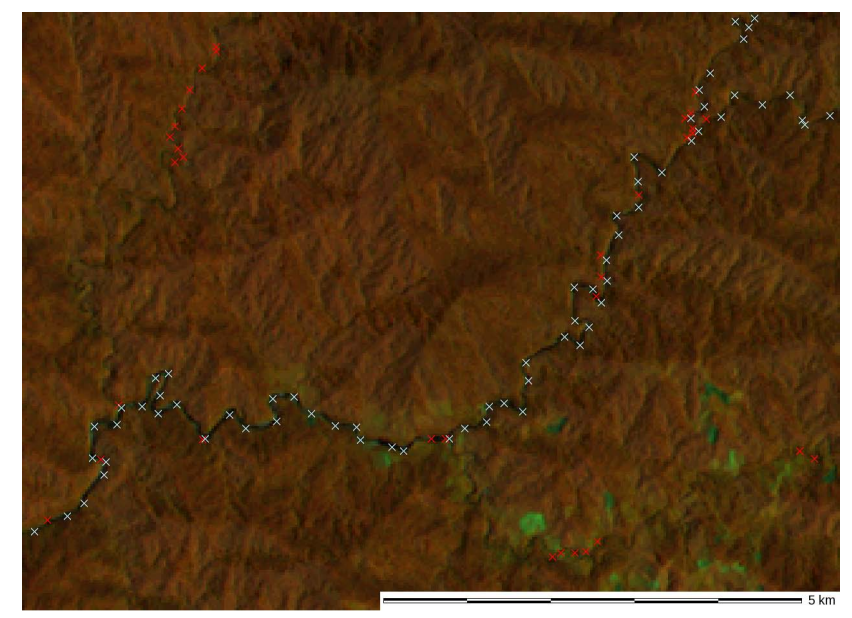

Fig. 3. Shaded relief of a Landsat false color composite (R,G,B = $4,5,3)$ overlaid with GPS reference points in red and points digitized from Landsat in grey.

(Andersen et al., 2006). IFSARE (InterFerometric Synthetic Aperture Radar - Elevation) is derived in a way very similar to SRTM, with the main difference that IFSARE is airborne and SRTM data was recorded with sensors onboard the Space Shuttle Endeavour. Both IFSARE and SRTM used two antennas to collect radar data; elevation information was derived by analyzing the data recorded by the two antennas (the general concept of the new satellite-borne TanDEM-X mission is similar, collecting radar data with two antennas). Neither of the surveys penetrated the forest canopy to the ground surface and the elevation surface was over large regions defined by a triple canopy tropical forest environment with tree heights of more than $30 \mathrm{~m}$ above ground. Given the widespread use of the SRTM data, one of the important questions explored in this paper was whether such data are suitable for stream extraction at all, and if yes, what is the accuracy and which methods provide the most reliable results in this challenging environment.

SRTM v2 tiles covering all of Panama were combined and gaps in the dataset filled using the regularized spline with tension (RST) interpolation method (GRASS module r.fillnulls; Mitasova and Mitas, 1993). The seamless SRTM coverage was then reprojected with bicubic interpolation from geographic to the UTM zone $17 \mathrm{~N}$ coordinate system with $90 \mathrm{~m}$ resolution to keep reprojection modifications to a minimum. To evaluate the impact of resampling on stream extraction accuracy (see e.g. Valeriano et al., 2006) and to generate data for additional performance testing, the reprojected $90 \mathrm{~m}$ SRTM DEM was reinterpolated to $30 \mathrm{~m}$ resolution using the RST method.
The IFSARE data were provided as a $10 \mathrm{~m}$ resolution DEM (Kinner et al., 2005) in the UTM zone $17 \mathrm{~N}$ coordinate system and did not require additional processing. For additional testing purposes, the IFSARE DEM was downsampled to $30 \mathrm{~m}$ resolution using bicubic interpolation in order to have DEMs from two sources (SRTM and IFSARE) with different level of detail, but identical resolution of $30 \mathrm{~m}$.

\subsection{Stream location data}

Two sets of data points were used to evaluate horizontal accuracy of the drainage network extraction methods: (i) stream segments digitized from Landsat imagery (TM 5, year 2000, scene id LT50120542000087XXX02, provided by the United States Geological Survey - USGS) and (ii) GPS field measurements. Bands 3, 4, and 5 of the Landsat TM scene were used at its native resolution of $30 \mathrm{~m}$. The geographic projection for this study (UTM 17 North) was identical to the projection of this Landsat scene, i.e. the Landsat grid geometry and values were not modified. A Landsat false color composite with Red, Green, and Blue assigned to the channels 4,5 , and 3 respectively, clearly separated vegetation from waterbodies and provided the background for manual digitization of points along the river centerlines. Only streams and rivers with a width less or equal to 4 grid cells $(120 \mathrm{~m})$ were digitized in order to exclude lakes, anabranching or braided rivers, and rivers too broad to reliably determine a stream center using Landsat imagery (Fig. 3). The horizontal accuracy of these manually digitized reference points is given by the imagery resolution of $30 \mathrm{~m}$ or better, depending on the stream width and the location of the stream centerline in relation to the grid cells.

GPS points were collected in the field using a Corvallis Microtechnology March v3.7 GPS unit with $\sim 2 \mathrm{~m}$ positional accuracy. Sites in the Chagres river watershed were measured during the years 2002 to 2007 and sites at lower reaches of most major rivers across Panama were measured during 2005 and 2009 years. GPS points were collected along clearly identifiable perennial rivers at locations where a reliable GPS signal was available. The GPS measurements included a larger proportion of points acquired in mountainous regions along smaller rivers, while most of the points located along larger rivers in low-gradient flood plain and coastal plain landscapes were digitized from Landsat imagery (Fig. 3).

The SRTM water body database was not used for the accuracy evaluation because this cannot be regarded as an independent data source since it was used in the creation of the SRTM DEM v2, and because even the larger rivers visible on Landsat imagery were still too narrow to be captured in the SRTM water body database.

We have also considered and rejected the use of hydrography (blue lines) from topographic maps because of their low reliability and a relatively coarse scale of 1:50000. Several studies that have compared the blue lines with on-ground 

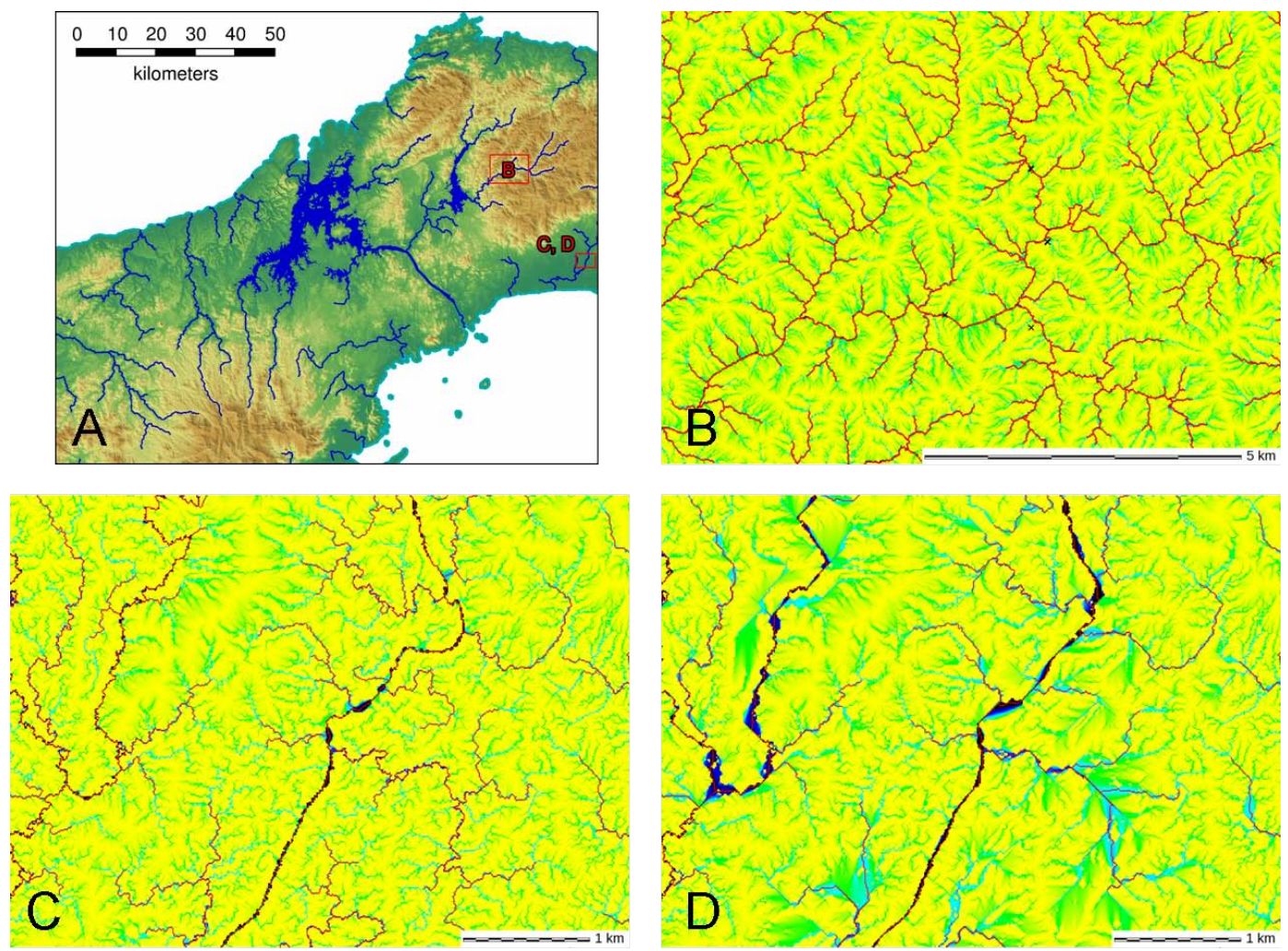

Fig. 4. Extraction of a single main channel: (A) Location of areas shown in images (B), (C), and (D); (B) The starting points of the extracted streams (red lines) were well upstream of the reference points (black crosses). Flow accumulation derived from IFSARE $10 \mathrm{~m}$ is used as background. The extracted streams (red lines) are located within broader stream tubes in low-gradient areas close to the coast, for both (C) LCP-derived streams and (D) streams derived with sink filling. IFSARE $10 \mathrm{~m}$ was used for both (C) and (D) representing the same area.

surveys of existing streams demonstrated that the blue lines were the least accurate source of stream location information (see e.g. Colson, 2006 and the references therein), often based on old data digitized from aerial photographs with large errors in locations where the streams were not visible, due to the presence of vegetation. In fact, one of the major motivations for deriving the drainage network from the IFSARE data in Panama was the inadequate scale of available blue lines with many larger streams missing and with errors in the mapped streams location. Until recently, the relative inaccessibility of some regions (e.g. the upper Chagres river) and an incessant cloud cover have discouraged mapping in these areas (Kinner et al., 2005).

\subsection{Flow accumulation and evaluation of extracted drainage networks}

Several tests were performed to evaluate the tested flow routing algorithms. The first test evaluated the processing speed and capability to handle large DEMs when computing flow accumulation maps. In this test, the performance of the new LCP implementation was compared with the old rwatershed module (GRASS Development Team, 2008) and with a relatively new, I/O-efficient algorithm, used in the module r.terraflow (Arge et al., 2003). All computations were done on the same hardware (AMD Athlon X2 $3 \mathrm{GHz}$ and $8 \mathrm{~GB}$ RAM) but different operating systems (Linux 64 bit for the GRASS modules r.watershed and r.terraflow, and Windows XP 32 bit for TAS GIS which is a 32 bit application for Microsoft Windows and was not available as 64 bit application at the time of writing).

The second test evaluated the horizontal accuracy of the extracted drainage paths for algorithms with different handling of depressions. Three approaches were tested: (i) sink filling as implemented in r.terraflow, (ii) the impact reduction approach (IRA) as implemented in TAS GIS (Lindsay and Creed, 2005), and (iii) the LCP algorithm as implemented in the enhanced version of r.watershed in GRASS GIS 6.4. To test the sink filling method, r.terraflow was used because of its capability to efficiently process massive DEMs.

The third test evaluated the impact of DEM resolution and level of detail on the horizontal accuracy of the extracted drainage paths for all tested algorithms (r.watershed, r.terraflow, and TAS).

The tests were performed for the central Panama region using both the IFSARE and SRTM data at the $10 \mathrm{~m}, 30 \mathrm{~m}$ and $90 \mathrm{~m}$ resolutions by computing flow accumulation with 
MFD dispersal and extracting drainage networks from the computed flow accumulation.

Drainage networks were extracted from all MFD flow accumulation maps using a minimum upstream catchment area of $100000 \mathrm{~m}^{2}$ as a threshold. This threshold was selected for testing purposes and to ensure that all measured or digitized points were located downstream from the extraction starting point and that all points had a drainage path associated with it (Fig. 4b). Accurate identification of the channel head zones was beyond the scope of this paper because it requires more than elevation data as it is often significantly influenced by local geology, groundwater level, and land cover (North Carolina Division of Water Quality NCWQ, 2010). According to the NCWQ (2010) study, "the stream origins usually occur as transition zones in which the location and length of the zone is subject to fluctuations in groundwater levels and precipitation". The tested $90 \mathrm{~m}$ and $30 \mathrm{~m}$ resolution SRTM DEMs measured over at least $30 \mathrm{~m}$ high canopy of dense tropical forest did not provide sufficient information for accurate identification and mapping of the dynamic channel heads zones. Therefore our focus was on mapping streams and rivers that have sufficiently large contributing areas that the existence of a well defined stream can be expected.

In order to extract a single main channel in broader floodplains where MFD flow accumulation generates several cells wide stream tubes that may include cells above the given threshold, a new stream starting point was defined only if it was not located within such a stream tube (Fig. 4). Downstream channel tracing followed the steepest slope and maximum flow accumulation within the stream tube. To egress from depressions using the LCP method, streams again followed the maximum flow accumulation which was in these cases identical to the drainage direction initially determined during the LCP search. As a result, the drainage paths extracted from MFD flow accumulation were a single grid cell wide and were easily vectorized for further analysis. This approach of extracting single cell wide dendritic and topologically correct drainage networks from flow accumulation obtained with any kind of flow distribution method avoids the problems associated with skeletonizing rasterized MFD channels. The MFD capabilities to map flow dispersal in floodplains can then be preserved and single flow direction (SFD) routing is not necessary for flow accumulation and subsequent channel extraction (although it remains an option).

Assessment of drainage network extraction accuracy was then performed by calculating distances between the drainage paths derived from the IFSARE and SRTM DEMs and the points measured along the streams, consisting of 338 on-ground GPS measurements and 995 points digitized along rivers from the Landsat imagery (Figs. 3, 4).

In order to determine which method or level of detail provided more accurate results, we determined the distance of reference points to the nearest extracted drainage path. The difference in the distance to reference points between methods or level of detail was then used to assess which method or level of detail provided more accurate results. Distance differences were tested with two-tailed Student's t-tests for statistical significance and $\alpha=0.05$. If distance differences were significantly different from zero, i.e. one of the tested methods/levels of detail was more accurate than the other, the sign of the difference indicated which method/level of detail was more accurate.

\section{Results}

\subsection{Performance comparison}

To demonstrate the improvement in computational performance of the new LCP method implementation, the processing times needed by the old and new version of r.watershed, and rterraflow were compared, with the results summarized in Table 1. For flow accumulation computation, the new version was 350 times faster than the old version for the central Panama area represented by a relatively small DEM with 2 million grid cells at $90 \mathrm{~m}$ resolution. The improvement was even more dramatic for the countrywide coverage at $90 \mathrm{~m}$ resolution with 27 million grid cells: the new version was about 1750 times faster. Although absolute processing times are dependent on the specific hardware used for testing, we expect that relative time differences will be similar on other systems because the software optimizations are hardware-independent. Processing the larger regions used in this study with the old version was impractical because it could easily take days (Arge et al., 2003), whereas the new version required only minutes to execute. The computational time needed by the I/O-efficient r.terraflow was significantly lower than that for the old r.watershed, but the r.terraflow module was not as fast as the new LCP implementation on our test system (Table 1). We have also considered the case when the data do not fit into memory and r.watershed uses segmented processing, with intermediate data being stored on disk. This leads to longer processing times than for the all-in-memory mode. Processing times observed on our testing system in the segmented mode were still shorter than for r.terraflow, which uses I/O-efficient algorithms specifically designed for large datasets (Arge et al., 2003). The size of intermediate data created by r.watershed in the segmented mode was less than $20 \%$ of those created by r.terraflow. This can be of advantage if intermediate data are just a bit too large to fit into memory. It is important to note that, theoretically, r.terraflow with its advanced I/O-efficient algorithms should be faster than r.watershed for DEMs much larger than the ones processed here and on systems with less physical memory.

TAS GIS was not included in the performance comparisons, because its memory requirements for processing the $10 \mathrm{~m}$ IFSARE DEM and the $30 \mathrm{~m}$ SRTM DEM for all of 
Table 1. Processing time for the different DEMs on a Linux 64 bit system with an AMD Athlon X2 3 GHz CPU and 8 GB RAM.

\begin{tabular}{llllll}
\hline & $\begin{array}{l}\text { SRTM 90 m } \\
\text { Central Panama } \\
1.9 \text { million cells }\end{array}$ & $\begin{array}{l}\text { IFSARE 30 m } \\
\text { central Panama } \\
17 \text { million cells }\end{array}$ & $\begin{array}{l}\text { SRTM 90 m } \\
\text { all of Panama } \\
27 \text { million cells }\end{array}$ & $\begin{array}{l}\text { IFSARE 10 m } \\
\text { central Panama } \\
156 \text { million cells }\end{array}$ & $\begin{array}{l}\text { SRTM 30 m } \\
\text { all of Panama } \\
\text { 241 million cells }\end{array}$ \\
\hline $\begin{array}{l}\text { old r.watershed, } \\
\text { all in memory }\end{array}$ & $23.2 \mathrm{~min}$ & $23 \mathrm{~h} 10 \mathrm{~min}$ & $30 \mathrm{~h} 46 \mathrm{~min}$ & $\begin{array}{l}>2 \text { days } \\
\text { not measured }\end{array}$ & $\begin{array}{l}>2 \text { days } \\
\text { not measured }\end{array}$ \\
\hline $\begin{array}{l}\text { new r.watershed, } \\
\text { all in memory }\end{array}$ & $0.07 \mathrm{~min}$ & $0.83 \mathrm{~min}$ & $1.05 \mathrm{~min}$ & $9.97 \mathrm{~min}$ & $12.3 \mathrm{~min}$ \\
\hline $\begin{array}{l}\text { new r.watershed, } \\
\text { data on disk }\end{array}$ & $0.15 \mathrm{~min}$ & $1.73 \mathrm{~min}$ & $2.05 \mathrm{~min}$ & $30.7 \mathrm{~min}$ & $32.18 \mathrm{~min}$ \\
\hline r.terraflow & $0.45 \mathrm{~min}$ & $4.4 \mathrm{~min}$ & $5.05 \mathrm{~min}$ & $66.95 \mathrm{~min}$ & $58.7 \mathrm{~min}$ \\
\hline
\end{tabular}

Table 2. Median distances of reference points to nearest extracted stream in meters.

\begin{tabular}{l|lll|lll}
\hline & $\begin{array}{l}\text { GPS } \\
\text { filling }\end{array}$ & IRA & LCP & $\begin{array}{l}\text { Landsat } \\
\text { filling }\end{array}$ & IRA & LCP \\
\hline IFSARE 10 m & 62.65 & N/A* & 34.40 & 43.75 & N/A* & 39.25 \\
IFSARE 30 m & 77.15 & 71.42 & 70.71 & 48.88 & 48.27 & 47.75 \\
SRTM 30 m & 99.78 & 92.46 & 89.13 & 84.25 & 82.81 & 83.72 \\
SRTM 90 m & 124.84 & 119.69 & 121.00 & 94.30 & 94.69 & 94.92 \\
\hline
\end{tabular}

* Computation cancelled by software with out of memory error.

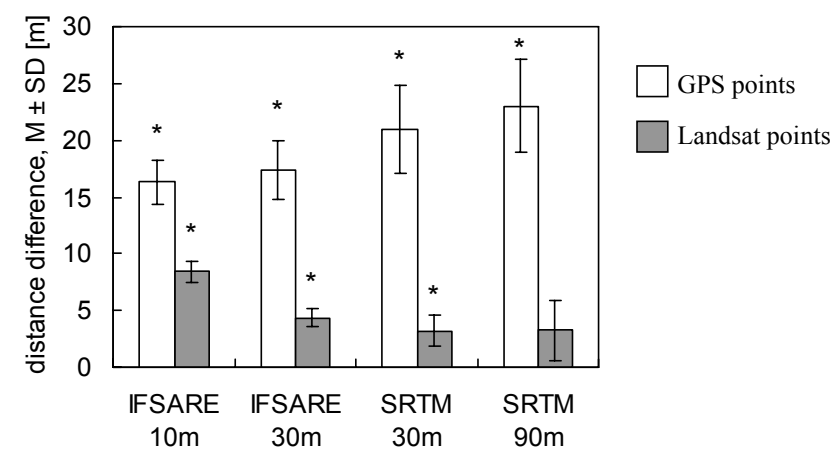

Fig. 5. Mean and standard deviation of the distance differences between sink filling and least-cost path search. A positive distance difference indicates that streams extracted with least-cost path search are closer to reference points than streams extracted with sink filling.

Panama exceeded available system memory. TAS GIS is a 32 bit application for Microsoft Windows and can only utilize as much memory as a 32 bit application can manage, i.e. $3 \mathrm{~GB}$. As opposed to r.terraflow and rwatershed, TAS GIS keeps all intermediate data in memory, thus limiting the size of the DEMs that can be processed. The test system provided as much memory as TAS GIS could theoretically uti-

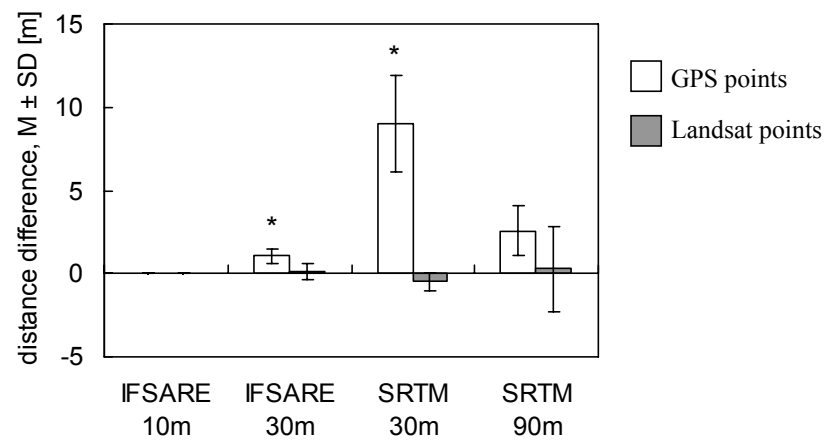

Fig. 6. Mean and standard deviation of the distance differences between impact reduction approach and least-cost path. A positive distance difference indicates that streams extracted with leastcost path search are closer to reference points than streams extracted with the impact reduction approach.

lize, hence the out-of-memory error was regarded as a limitation of this application and not as a hardware limitation. Therefore, TAS was used only for the sink treatment methods in comparison with the $30 \mathrm{~m}$ and $90 \mathrm{~m}$ DEM covering the central Panama subregion (Fig. 2) and results of the IRA method were not available for $10 \mathrm{~m}$ IFSARE. At the time of writing, IRA was not included in WhiteboxGAT (Lindsay, 2009) that has replaced TAS.

\subsection{Comparison between different methods of sink treatment}

To evaluate the impact of different approaches in the handling of elevation surface depressions, median distances of reference points to extracted drainage paths for each sink treatment method and each processed DEM were computed and the results are summarized in Table 2. As expected, the location of extracted drainage paths improved with increasing detail available in the DEM. While the drainage paths for 


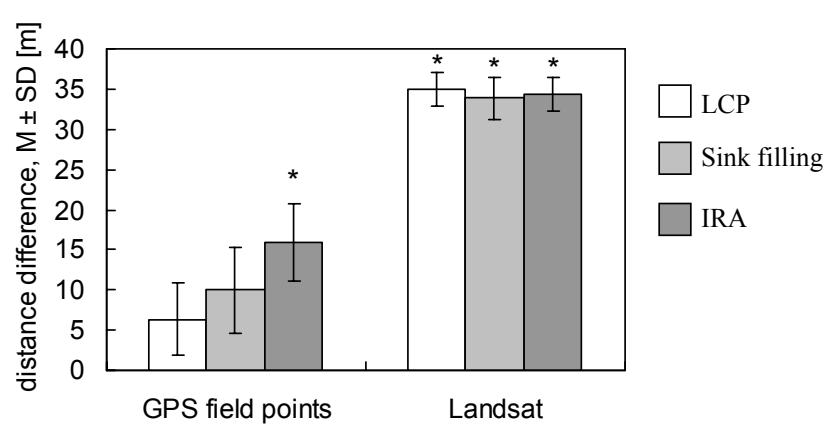

Fig. 7. Mean and standard deviation of the distance differences between the $30 \mathrm{~m}$ SRTM DEM and the $30 \mathrm{~m}$ IFSARE DEM. A positive distance difference indicates that streams extracted from the $30 \mathrm{~m}$ IFSARE DEM are closer to reference points than streams extracted from the $30 \mathrm{~m}$ SRTM DEM. LCP: least-cost path search; IRA: impact reduction approach.

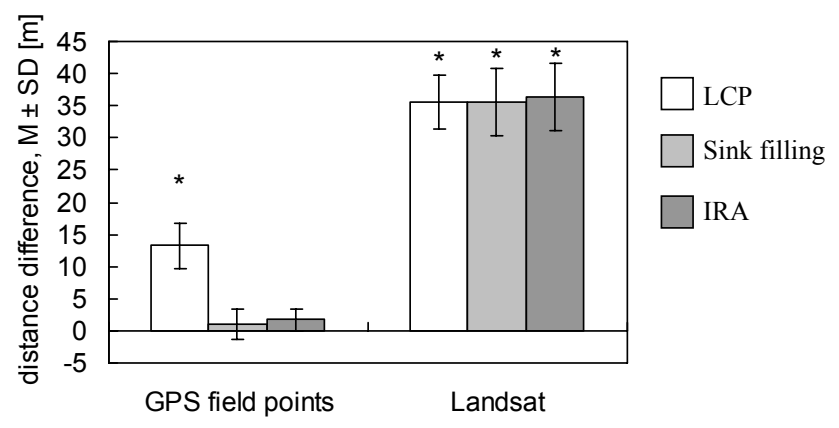

Fig. 8. Mean and standard deviation of the distance differences between the $90 \mathrm{~m}$ and the $30 \mathrm{~m}$ SRTM DEM. A positive distance difference indicates that streams extracted from the $30 \mathrm{~m}$ SRTM DEM are closer to reference points than streams extracted from the $90 \mathrm{~m}$ SRTM DEM. LCP: least-cost path search; IRA: impact reduction approach.

the $90 \mathrm{~m}$ SRTM DEM were about $100 \mathrm{~m}$ away from reference points, the median distances improved down to $34.4 \mathrm{~m}$ for the IFSARE $10 \mathrm{~m}$ DEM.

Drainage paths extracted from the LCP flow accumulation were closer to the GPS field points (t-tests, all $t_{337}<-5.4$, all $p<0.0001$ ) for all DEMs at all tested resolutions (IFSARE $10 \mathrm{~m}, 30 \mathrm{~m}$, and SRTM $30 \mathrm{~m}, 90 \mathrm{~m}$ ) when compared with the sink filling method (Fig. 5 showing bar graphs with mean and standard deviation of the distance differences). The drainage paths extracted from LCP were also closer to the points digitized from Landsat for all DEMs (t-tests, all $t_{994}<-2.3$, all $p<0.0001$ ), except for the $90 \mathrm{~m}$ SRTM where the distance difference was not significant for (t-test, $t_{994}=-1.213$, $p=0.23$ ).

When compared to the IRA method (Fig. 6 showing bar graphs with mean and standard deviation of the distance differences), drainage paths extracted from LCP flow accumulation were closer to the GPS field points for the $30 \mathrm{~m}$ IFSARE (t-test, $\left.t_{337}=-2.361, p=0.018\right)$ and $30 \mathrm{~m} \mathrm{SRTM} \mathrm{(t-test,}$ $\left.t_{337}=-3.088, p=0.002\right)$, but for the $90 \mathrm{~m}$ SRTM the difference was not significant (t-test, $t_{337}=-1.745, p=0.08$ ). For the points digitized from Landsat, drainage paths extracted from LCP accumulation were not closer than IRA drainage paths for any of the tested DEMs (t-tests, all absolute $t_{994}<1.0$, all $p>0.3$ ).

\subsection{Comparison between different levels of detail at constant resolution}

The $10 \mathrm{~m}$ IFSARE and $90 \mathrm{~m}$ SRTM were interpolated to the same resolution of $30 \mathrm{~m}$. We investigated how much the different levels of detail at identical resolution influenced the accuracy of extracted drainage paths for all three sink treatment methods (Fig. 7 showing bar graphs with mean and standard deviation of the distance differences). The distance between the reference points and drainage paths extracted from the $30 \mathrm{~m}$ IFSARE DEM was subtracted from the distance between the reference points and drainage paths extracted from the $30 \mathrm{~m}$ SRTM DEM to measure the difference in accuracy of drainage paths extracted from these two DEMs. For larger rivers in flat areas (Landsat points), the accuracy of drainage path locations was considerably higher for the $30 \mathrm{~m}$ IFSARE DEM than for the $30 \mathrm{~m}$ SRTM DEM (t-test, all $t_{994}<-13.0$, all $p<0.001$; on average $35 \mathrm{~m}$ closer) for all methods. For smaller rivers not broader than $30 \mathrm{~m}$ in mountainous regions (GPS points), only IRA showed a significant improvement in accuracy from the $30 \mathrm{~m}$ SRTM DEM to the $30 \mathrm{~m}$ IFSARE DEM (t-test, $t_{337}=-3.315, p=0.001$, all other $t_{337}>-1.9$ and $<0, p>0.05)$. However, as shown in the previous section for the $30 \mathrm{~m}$ IFSARE DEM, IRA drainage path locations in mountainous regions were significantly less accurate than LCP drainage path locations.

\subsection{Effects of RST resampling on the accuracy of drainage network extraction}

In order to assess the effect of SRTM resampling from $90 \mathrm{~m}$ to $30 \mathrm{~m}$ resolution by the RST method, the drainage paths extracted from the $90 \mathrm{~m}$ SRTM DEM were compared with drainage paths extracted from the resampled $30 \mathrm{~m}$ SRTM DEM by calculating the difference in drainage path distances to reference points (Fig. 8 showing bar graphs with mean and standard deviation of the distance differences). Corresponding median distances of reference points to drainage path locations are given in Table 2. The accuracy of drainage path locations was improved by resampling for larger rivers in flat landscape for all sink treatment methods (t-tests, all $t_{994}<$ -6.5 , all $p<0.001$ ), however, for GPS points in mountainous regions only the results obtained by the least-cost path search were improved (t-test, $t_{337}=-3.734, p<0.001$, all other $t_{337}>-1$ and $\left.<0, p>0.3\right)$. 

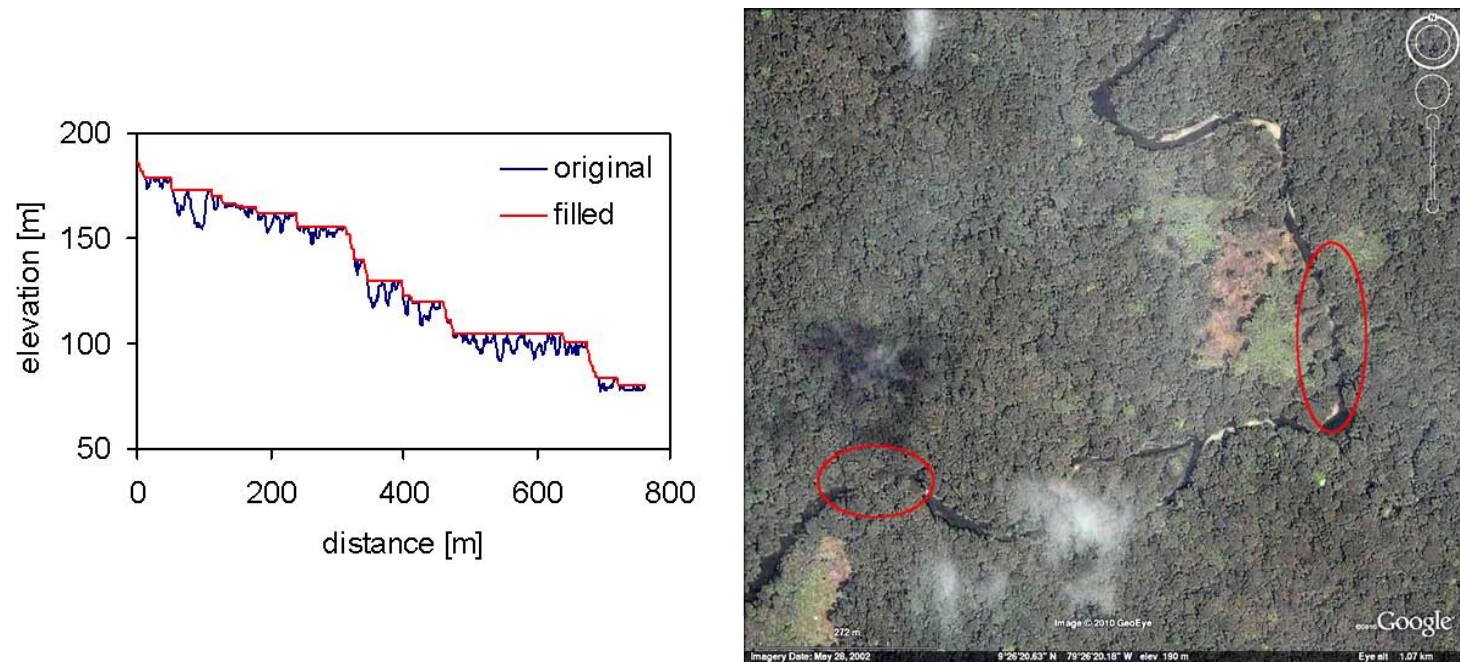

Fig. 9. A typical example for the impact of sink filling along a section of a river course extracted from the $30 \mathrm{~m}$ SRTM DEM. Along this section, $92 \%$ of all elevation values were modified. Parts of the river course obscured by trees are highlighted in the GoogleEarth sreenshot.

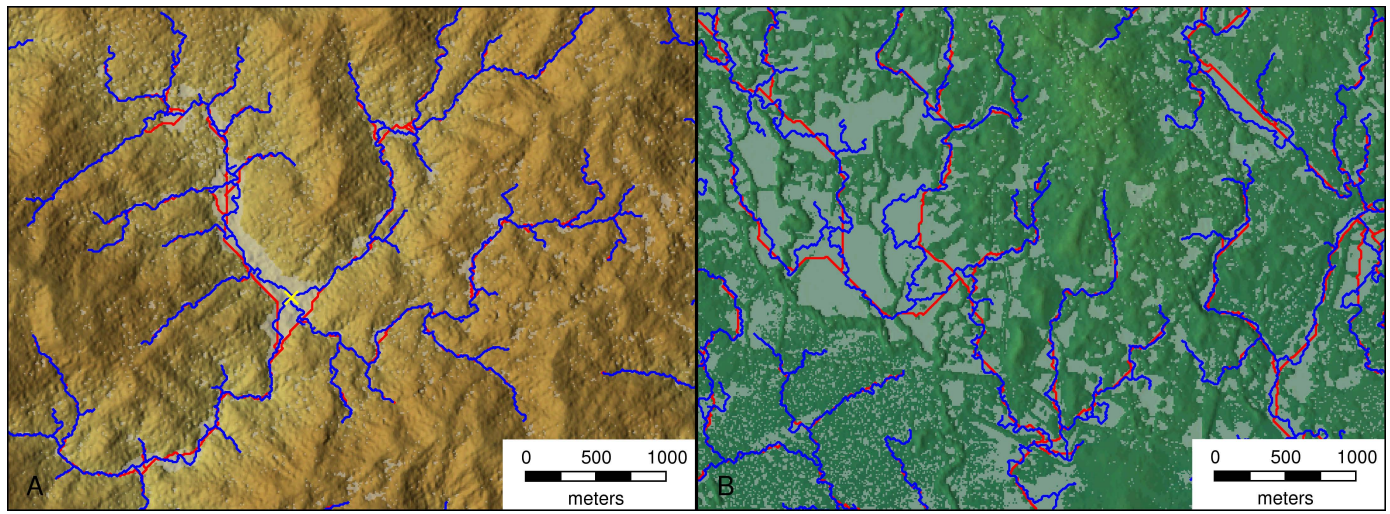

Fig. 10. Typical effects of different sink treatment methods on extracted stream courses in (A) mountainous areas and (B) costal plains. Filled sinks are grayed. Streams extracted from sink-filling in red are overlaid by streams extracted from least-cost path search in blue. Points of confluences (yellow cross) in mountainous areas can be shifted considerably, and in coastal plains, sink filling can lead to long straight lines. A shaded relief of the $10 \mathrm{~m}$ IFSARE DEM was used as background.

\section{Discussion}

Digital Terrain Models, as an approximation of real terrain at a given level of detail, include random noise and errors. For example, an in depth analysis of SRTM accuracy and source of errors is provided by Rodriguez et al. (2006) and Farr et al. (2007). The errors can have significant impact on the results of DEM analysis and their treatment has been the focus of broad research (e.g. Jenson and Domingue, 1988; Lindsay and Creed, 2005; Hutchinson, 2000). Sink (depression) removal was designed to remove small depressions introduced as artifacts of elevation data processing for the first generation of DEMs to facilitate continuous flow routing (Jenson and Domingue, 1988). This procedure, referred to as hydrological conditioning, has become widespread even for next generations of elevation data and is now a pre-processing step required by a number of applications for hydrological analysis and modeling. In order to alleviate the problem of routing surface flow through the flat areas created by sink filling, efforts have been made to add a gradient to these flat areas (e.g. Martz and Garbrecht, 1998; Wang and Liu, 2006; Grimaldi et al., 2007; Santini et al., 2009) Nevertheless, as modern high resolution data such as LiDAR demonstrate, actual terrain includes many true depressions, especially in riffle-and-pool portions of mountainous rivers, and on floodplains and coastal plains (Notebaert et al., 2009). Therefore, sink filling is not always an appropriate approach for hydrological conditioning of a DEM because the measured elevation data are replaced with new elevation values based on the rather unrealistic assumption that the terrain has no depressions (Jenson and Domingue, 1988; Tarboton, 1997), 
be they artificial or real. Although many hydrologic models require depression-less DEMs, removal of sinks can alter the true hydrological state that includes standing water in depressions. Moreover, in IFSARE and SRTM DEMs that include vegetation cover, many of the observed depressions are caused by gaps in canopy, canopy closing over river courses, or by vegetation partially obstructing narrow and deep valleys. The filling of such features requires altering elevations by several meters and over areas of hundreds of $\mathrm{m}^{2}$, leading to large flats and an artificial drainage network geometry that does not represent reality. Figure 9 presents an example of the barriers across the river channel created by overhanging trees and a profile that illustrates the extensive modification in elevation that can result from such filling. Preserving most of the drainage directions of the original DEM is preferable to hydrological conditioning in this case.

Our results suggest that the adverse effects of sink filling become more pronounced for higher resolution DEMs (see Fig. 10 for drainage paths extracted from $10 \mathrm{~m}$ IFSARE). By contrast, at lower resolutions such as $90 \mathrm{~m}$, the coarsest resolution tested in this study, there was often no significant difference in drainage path locations between the compared methods, particularly for Landsat reference points. Landsat points where predominantly located in flood plain and coastal plain landscapes where both the horizontal and the vertical resolution of $90 \mathrm{~m}$ SRTM were often not sufficient to locate rivers and no method was able to accurately delineate drainage paths in these areas from $90 \mathrm{~m}$ SRTM (Hancock et al., 2006; Valeriano et al., 2006).

When comparing SRTM and IFSARE DEMs at the same resolution of $30 \mathrm{~m}$, the drainage networks extracted from the IFSARE DEM were, as expected, more accurate than drainage networks extracted from SRTM DEM, particularly for Landsat points in relatively flat areas. As shown in previous studies (Hancock et al., 2006; Valeriano et al., 2006), the SRTM DEM close to its native resolution of $3 \mathrm{arc} \mathrm{sec}$ does not provide sufficient vertical detail to determine river courses in flat areas. The applied RST resampling method significantly improved the accuracy of extracted drainage path locations for SRTM in regions with low topography. Apparently the level of detail has been not just increased but also improved because resampling to a higher horizontal (and for SRTM also higher vertical) resolution seems to be helpful in improving the results of watershed analysis from lowresolution DEMs (see also Valeriano et al., 2006). The global SRTM coverage at 3 arc sec horizontal resolution has been created by averaging the original 1 arc sec coverage (Farr et al., 2007). Depending on the method used, reinterpolating the 3 arc sec version back to 1 arc sec can result in narrowed valleys and ridges and increased channel sinuosity. Interestingly, only the LCP search method benefited from the reinterpolation in mountainous regions and provided here the most accurate drainage path locations for the $30 \mathrm{~m}$ SRTM DEM.

It is important to note that the differences in the tested methods were significant due to the particularly challenging study region. Smaller differences between the methods could be expected in topography with gentle slopes and uniformly low vegetation cover. Although network connectivity, topology and channel morphometry has not been investigated, the visual inspection of the results indicates that there were differences between the results obtained by different methods and resolutions in the coastal plain areas. None of the tested DEMs or methods produced sufficiently reliable results and higher resolution did not always lead to correct topology. These results are similar to those found for LiDAR-based DEMs (Colson, 2006) and require further research.

Although the tests presented here demonstrated the performance of the LCP method for radar-based data, the new, improved version of rwatershed has in fact been developed using LiDAR data provided by the USGS in addition to the $1 \mathrm{~m}$ LiDAR DEM examples and data provided by Neteler and Mitasova (2008). The presented method processes a DEM without modifying its elevation values and is thus to a degree (quantitatively narrowed by this study) dependent on the reliability of the provided DEM. The LCP search approach, despite its capability to route flow through depressions, will therefore, like other methods, fail to accurately extract drainage networks if the input DEM deviates too far from real topography.

\section{Conclusions}

We presented a method for fast computation of flow accumulation and drainage network extraction for large DEMs with nested depressions and evaluated it against other commonly used methods for sink treatment. The accuracy assessment using ground control points and Landsat satellite imagery provided insight into the accuracy of drainage network extraction from radar elevation data in a challenging tropical forest environment and coastal plain setting. The results suggest that the conceptually simple sink filling approach is not suitable for the IFSARE and SRTM DEMs in regions with significant vegetation cover whereas both the tested impact reduction approach of Lindsay and Creed (2005) and the LCP search provide more accurate drainage networks.

The performance testing has demonstrated that the new implementation dramatically improves computational efficiency while preserving the high accuracy of the LCP routing capabilities. The increase in computational performance is particularly relevant for the modern mapping technologies that can rapidly produce massive DEMs at high resolutions for large areas and the slow processing and analysis has become bottleneck in their application. Fast processing of massive DEMs opens their application to a new level of detail and spatial extent, for example in rapid response operations or for mapping in remote regions where the streams are covered by dense vegetation and no reliable stream data are available. 
Acknowledgements. The support of the US Army Research Office for this research is gratefully acknowledged. We would also like to thank two anonymous reviewers for their valuable comments.

Edited by: R. Purves

\section{References}

Andersen, H. E., Reutebuch, S. E., and McGaughey, R. J.: Accuracy of an IFSAR-derived digital terrain model under a conifer forest canopy, Can. J. Remote Sens., 31, 283-288, 2005.

Arge, L., Chase, J. S., Halpin, P. N., Toma, L., Vitter, J. S., Urban, D., and Wickremesinghe, R.: Flow computation on massive grid terrains, GeoInformatica, 7, 283-313, 2003.

Atkinson, M. D., Sack, J.-R., Santoro, N., and Strothotte, T.: Minmax heaps and generalized priority queues, Programming techniques and Data structures, Comm. ACM, 29, 996-1000, 1986.

Colson, T. P.: Stream network delineation from high-resolution digital elevation models, Ph.D. Dissertation, Department of Forestry \& Environmental Resources, North Carolina State University, Raleigh, NC, available at http://www.lib.ncsu.edu/theses/ available/etd-10302006-122024/, 2006.

Costa-Cabral, M. C. and Burges, S. J.: Digital elevation model networks (DEMON): A model of flow over hillslopes for computation of contributing and dispersal areas, Water Resour. Res., 30, 1681-1692, 1994.

Danner, A., Yi, K., Moelhave, T., Agarwal, P. K., Arge, L., and Mitasova, H.: TerraStream: From Elevation Data to Watershed Hierarchies, Proc. ACM GIS, 28, doi:10.1145/1341012.1341049, 2007.

Ehlschlaeger, C.: Using the A* Search Algorithm to Develop Hydrologic Models from Digital Elevation Data, Proceedings of International Geographic Information Systems (IGIS) Symposium, Baltimore, MD, USA, 275-281, 1989.

Fairfield, J. and Leymarie, P.: Drainage networks from grid digital elevation models, Water Resour. Res., 27, 709-717, 1991.

Farr, T. G., Rosen, A. R., Caro, E., Crippen, R., Duren, R., Hensley, S., Kobrick, M., Paller, M., Rodriguez, E., Roth, L., Seal, D., Shaffer, S., Shimanda, J., Umland, J., Werner, M., Oskin, M., Burbank, D., and Alsdorf, D.: The Shuttle Radar Topography Mission, Rev. Geophys., 45, RG2004, doi:10.1029/2005RG000183, 2007.

Freeman, T. G.: Calculating catchment area with divergent flow based on a regular grid, Comput Geosci., 17, 413-422, 1991.

Garbrecht, J. and Martz, L. W.: The assignment of drainage direction over flat surfaces in raster digital elevation models, J. Hydrol., 192, 204-213, 1997.

GRASS Development Team: Geographic Resources Analysis Support System (GRASS) Software, Version 6.3.0. http://grass. osgeo.org/download/software_old.php\#g630, 2008.

GRASS Development Team: Geographic Resources Analysis Support System (GRASS) Software, Version 6.4.0, Open Source Geospatial Foundation, http://grass.osgeo.org, 2010.

Grimaldi, S., Nardi, F., Di Benedotto, F., Istanbulluoglu, E., and Bras, R. L.: A physically-based method for removing pits in digital elevation models, Adv. Water Resour., 30, 2151-2158, 2007.

Hancock, G. R., Martinez, C., Evans, K. G., and Moliere, D. R.: A comparison of SRTM and high-resolution digital elevation models and their use in catchment geomorphology and hydrology:
Australian examples, Earth Surf. Proc. Land., 31, 1394-1412, 2006.

Hart, P. E., Nilsson, N. J., and Raphael, B.: A Formal Basis for the Heuristic Determination of Minimum Cost Paths, IEEE T. Syst. Sci. Cyb., 4, 100-107, 1968.

Holmgren, P.: Multiple flow direction algorithms for runoff modeling in grid based elevation models: An empirical evaluation, Hydrol. Process., 8, 327-334, 1994.

Jenson, S. K. and Domingue, J. O.: Extracting topographic structure from digital elevation data for geographic information system analysis, Photogramm. Eng. Rem. S., 54(11), 1593-1600, 1988.

Kinner, D., Mitasova, H., Harmon, R. S., Toma, L., and Stallard, R.: GIS-based Stream Network Analysis for The Chagres River Basin, Republic of Panama. In: Harmon R (ed) The Rio Chagres: A Multidisciplinary Profile of a Tropical Watershed, Springer/Kluwer, 83-95, 2005.

Lehner, B. and Döll, P.: Development and validation of a global database of lakes, reservoirs and wetlands, J. Hydrol., 296, 1-22, 2004.

Lindsay, J. B.: Whitebox http://www.uoguelph.ca/ hydrogeo/ Whitebox/index.html, 2009.

Lindsay, J. B. and Creed, F.: Removal of artefact depressions from digital elevation models: towards a minimum impact approach, Hydrol. Process., 19, 3113-3126, 2005.

Martz, L. W. and Garbrecht, J.: The treatment of flat areas and depressions in automated drainage analysis of raster digital elevation models, Hydrol. Process., 12, 843-855, 1998.

Metz, M. and Ehlschlaeger, C.: Watershed analysis program r.watershed, source code, https://rac.osgeo.org/grass/browser/ grass/branches/releasebranch_6_4/raster/r.watershed, 2010.

Mitasova, H. and Mitas, L.: Interpolation by Regularized Spline with Tension: I. Theory and Implementation, Math. Geol., 25, 641-655, 1993.

Neteler, M. and Mitasova, H.: Open Source GIS: A GRASS GIS Approach, Third Edition, Springer New York, 406 pp., 2008.

North Carolina Division of Water Quality (NCWQ): Methodology for Identification of Intermittent and Perennial Streams and Their Origins, Version 4.1.1, http://portal.ncdenr.org/web/ wq/swp/ws/401/waterresources/streamdeterminations, Effective Date: 1 September 2010.

Notebaert, B., Verstraeten, G., Govers, G., and Poesen, J: Qualitative and quantitative applications of LiDAR imagery in fluvial geomorphology, Earth Surf. Proc. Landforms, 34, 217-231, 2009.

O'Callaghan, J. F. and Mark, D. M.: The Extraction of Drainage Networks from Digital Elevation Data, Computer Vision, Graphics, and Image Processing, 28, 223-344, 1984.

Peckham, S. D.: Efficient extraction of river networks and hydrologic measurements from digital elevation data, in BarndorffNielsen and others, eds., Stochastic Methods in Hydrology: Rain, Landforms and Floods: Singapore, World Scientiifc, 173203, 1998.

Planchon, O. and Darboux, F.: A fast, simple and versatile algorithm to fill the depressions of digital elevation models, Catena, 46, 159-176, 2001.

Quinn, P., Beven, K., Chevallier, P., and Planchon, O.: The prediction of hillslope flow paths for distributed hydrological modelling using digital terrain models, Hydrol. Process., 5, 59-79, 1991. 
Quinn, P. F., Beven, K. J., and Lamb, R.: The $\ln (\mathrm{a} / \mathrm{tan} / \mathrm{B})$ index: How to calculate it and how to use it within the topmodel framework, Hydrol. Process., 9, 161-182, 1995.

Rieger, W.: A phenomenon-based approach to upslope area and depressions in DEMs, Hydrol. Process., 12, 857-872, 1998.

Rivix Limited Liability Company: RiverTools ${ }^{\mathrm{TM}}$ User's Guide release 2001, Boulder, CO, Research Systems, Inc., 202 pp., 2001.

Rodriguez, E., Morris, C. S., and Belz, J. E.: A global assessment of the SRTM performance, Photogramm. Eng. Rem. S., 72, 249260, 2006.

Santini, M., Grimaldi, S., Rulli, M. C., Petroselli, A., and Nardi, F.: Pre-processing algorithms and landslide modeling on remotely sensed DEMs, Geomorphology, 113, 110-125, 2009.
Tarboton, D. G.: A New Method for the Determination of Flow Directions and Contributing Areas in Grid Digital Elevation Models, Water Resour. Res., 33, 309-319, 1997.

Valeriano, M. M., Kuplich, T. M., Storino, M., Amaral, B. D., Mendes, J. N., and Lima, D. J.: Modeling small watersheds in Brazilian Amazonia with shuttle radar topographic mission 90m data, Comput. Geosci., 32, 1169-1181, 2006.

Wang, L. and Liu, H. An efficient method for identifying and filling surface depressions in digital elevation models for hydrologic analysis and modelling, Int. J. Geogr. Inf. Sci., 20, 193-213, 2006.

World Wildlife Fund, HydroSHEDS, http://hydrosheds.cr.usgs.gov/ index.php, 2009. 